\title{
Development of Polypyrrole-Methylene Blue Nanoparticles for the Combination of Photothermal and Photodynamic Therapies ${ }^{\dagger}$
}

\author{
Thi Tuong Vy Phan ${ }^{1,2}$ \\ 1 Center for Advanced Chemistry, Institute of Research and Development, Duy Tan University, 03 Quang \\ Trung, Hai Chau, Danang 550000, Vietnam; phanttuongvy4@duytan.edu.vn \\ 2 Faculty of Environmental and Chemical Engineering, Duy Tan University, 03 Quang Trung, Hai Chau, \\ Danang 550000, Vietnam \\ + Presented at the 1st International Electronic Conference on Pharmaceutics, 1-15 December 2020; Available \\ online: https://iecp2020.sciforum.net/. \\ Published: date
}

\begin{abstract}
Combined therapy can be a highly promising strategy efficacy in the treatment of cancer with minimum side effects. The combination of photothermal therapy (PTT) and photodynamic therapy (PDT) has recently gained much attention due to its selective and localized therapeutic effects by light irradiation. The contrast agents for photo-based therapy should have a large absorption coefficient in the near-infrared region (NIR) $(700-2500 \mathrm{~nm})$ where the light has its maximum depth of penetration in tissues. In this work, we reported a multifunctional nanoparticle that has strong NIR absorbing capability for the combination of PTT and PDT. Methylene blue (MB) is a common photosensitizer for PDT in clinical use. Polypyrrole (PPy) is a super material for PTT because of its superior inherent features including strong NIR absorption, photothermal stability, low cost, and biocompatibility. For the first time, methylene blue (MB) was conjugated with photothermal material polypyrrole (PPy) to form a novel NIR photo-absorber. A fast and costeffective method was developed to prepare the MB-PPy nanoparticles. The in vitro test evidenced that PPy-MB NPs able to kill the cancer cells with the assistance of the NIR laser. Therefore, the novel PPy-MB NPs could be considered as promising single multifunctional nanoplatforms for further applications of photo-induced therapy.
\end{abstract}

Keywords: polypyrrole-methylene blue nanoparticles; photothermal therapy; photodynamic therapy; cancer treatment; NIR

\section{Introduction}

The combination of photothermal therapy (PTT) and photodynamic therapy (PDT) can be a highly promising strategy to enhance anticancer efficacy with minimum side effects [1]. There a need for developing the photo-absorber for this strategy. In this work, we combined polypyrrole (PPy) which have strong NIR absorption, photothermal stability, low cost, and biocompatibility [2], [3] with Methylene blue (MB) which is a common photosensitizer for PDT in clinical use with the cheap price [4] to create the novel NIR photo-absorber for a combination of PTT and PDT. The in vitro test evidenced that the PPy-MB NPs able to kill the cancer cells with NIR laser irradiation. Therefore, the PPy-MB NPs have the potential as single multifunctional nanoplatforms for NIR photo-induced therapy. 


\section{Materials and Methods}

\subsection{Materials}

Pyrrole (Py, reagent grade, 98\%), methylene blue (MB), polyvinyl alcohol (PVA, Mw: 9000$10,000)$, ferric chloride hexahydrate $\left(\mathrm{FeCl}_{3} .6 \mathrm{H}_{2} \mathrm{O}\right)$, dimethyl sulfoxide (DMSO), sodium dodecyl sulfate (SDS), 1,3-diphenyisobenzofuran (DPBF), and 3-(4,5-dimethylthiazol-2-yl)-2,5diphenyltetrazolium bromide (MTT) were purchased from Sigma-Aldrich (St. Louis, MO, USA). Breast cancer cells MDA-MB-231 were purchased from Korean Cell Line Bank. Cellular staining reagents were also purchased from Sigma-Aldrich (St. Louis, MO, USA). Cell media were purchased from HyClone (South Logan, UT, USA).

\subsection{Synthesis of PPy-MB NPS}

Briefly, $10 \mathrm{mg}$ of SDS and $1.50 \mathrm{~g}$ PVA were dissolved in $20 \mathrm{ml} \mathrm{DW}$ at $60^{\circ} \mathrm{C}$ for $20 \mathrm{~min}$. At first, the amount of $\mathrm{MB}$ was added to the above solution under the continuous stirring condition for 10 $\mathrm{min}$. Then the solution obtained was cooled to room temperature. $\mathrm{Next}, 0.67 \mathrm{~g} \mathrm{FeCl} 3.6 \mathrm{H}_{2} \mathrm{O}$ was added to the stirred PVA solution. After $1 \mathrm{~h}$ of equilibration, pyrrole monomer $(72 \mu \mathrm{L})$ was put into the above PVA/iron cation complex. The mixture turned black after a few min and the chemical oxidation polymerization of pyrrole was carried out for $4 \mathrm{~h}$. After that, the obtained nanoparticles were collected by centrifugation and were washed several times with hot water to extrude impurities.

\subsection{In Vitro Combined PTT and PDT}

The damaged and the dead cells were determined using the PI staining to evaluate the efficacy of combined PTT and PDT treatment. the MDA-MB-231 cells were seeded in a 12-well plate at a density of $1 \times 10^{5}$ cells/well. Then, the cells were treated with the PPy NPs $(50 \mu \mathrm{g} / \mathrm{mL})$ and PPy-MB $\mathrm{NPs}(50 \mu \mathrm{g} / \mathrm{mL})$ for $24 \mathrm{~h}$ and unbound nanoparticles were washed with PBS. After that, the cells were exposed to NIR laser at a power density of $0.5 \mathrm{~W} / \mathrm{cm}^{2}$ for $6 \mathrm{~min}$. Cells with and without nanoparticles which had not been exposed to the laser irradiation were also prepared for the comparison. Next, the cell plates were kept for a further $4 \mathrm{~h}$ in the incubator. Then the treated and untreated cells were stained with PI and the fluorescent images were taken.

\section{Results and Discussions}

\subsection{TEM and $U V$-Vis Absorption of PPy-MB NPs}

As shown in Figure 1a, the obtained PPy-MB NPs have a nearly spherical shape and quite uniform with a diameter of less than $100 \mathrm{~nm}$. The UV-Vis absorption spectrum revealed that PPy-MB NPs have strong absorption in the NIR region (Figure 1b).

a)

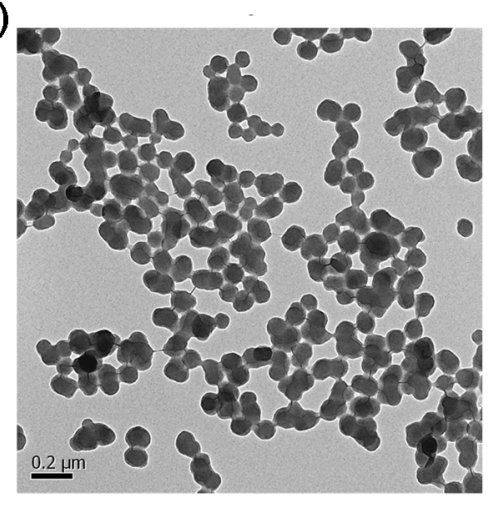

b)

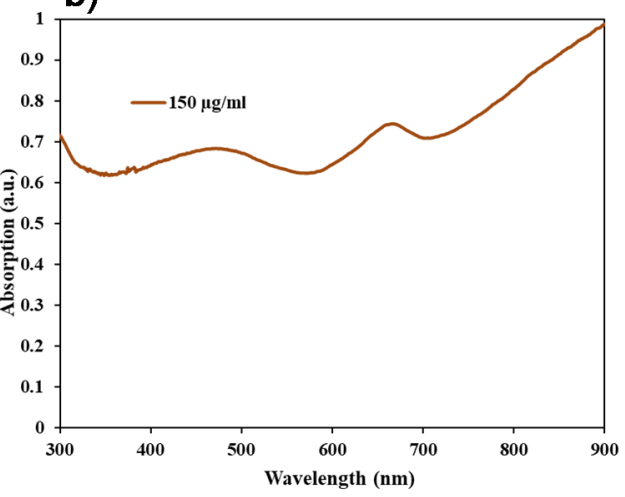

Figure 1. (a) TEM and (b) UV-Vis absorption spectrum of PPy-MB NPs. 


\subsection{In Vitro Combined PTT and PDT}

We compared the killing capability of cancer cells by the fluorescence imaging techniques of five groups: the control groups (only cells), the laser only group (cells were treated with $808 \mathrm{~nm}$ laser), the PPy NPs group $+808 \mathrm{~nm}$ laser (cells were treated with PPy NPs $+808 \mathrm{~nm}$ laser), and the PPy-MB $\mathrm{NPs}+808 \mathrm{~nm}$ laser group (cells were treated with PPy-MB NPs $+808 \mathrm{~nm}$ laser). The PI staining technique was used to explore the damaged and dead cells. As shown in Figure 2, only a few dead cells with the red nuclei were observed in the control, laser only, and the PPy-MB NPs group. In contrast, almost cells in the PPy-MB NPs $+808 \mathrm{~nm}$ laser group died with the red nuclei. The cancer cell death by PPy-MB NPs $+808 \mathrm{~nm}$ laser group could be due to two main factors, including ROS, owing to MB; and heating, owing to PPy. The data indicated that the PPy-MB NPs can be used for NIR-induced combined therapy and much more effective than a single therapy.

a) Control

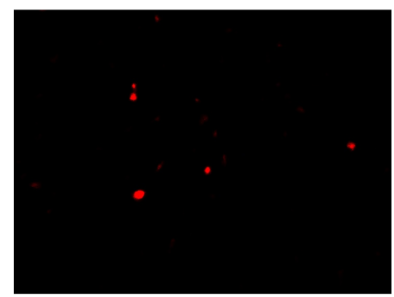

b) Laser only

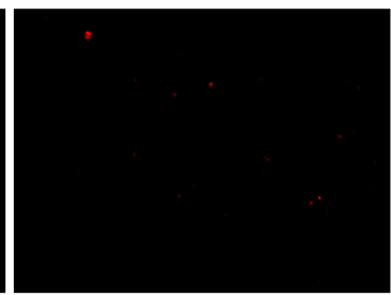

c) PPy Nps + Laser

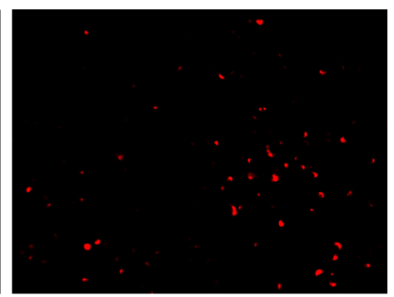

d) PPy-MB Nps + Laser

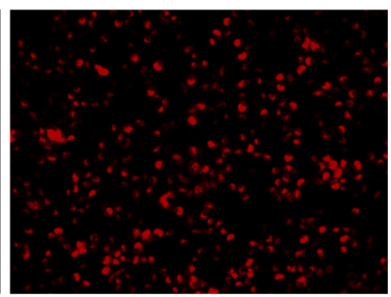

Figure 2. Fluorescence images of MDA-MB-231 cells under different conditions. (a) Control, (b) Laser only (808 nm laser), (c) PPy NPs + 808 nm laser, and (d) PPy-MB NPs + $808 \mathrm{~nm}$ laser. The concentration of PPy-MB NPs was $50 \mu \mathrm{g} / \mathrm{mL}$ and the $808 \mathrm{~nm}$ laser $\left(0.5 \mathrm{~W} / \mathrm{cm}^{2}\right)$ irradiation was carried out for $6 \mathrm{~min}$.

\subsection{Intracellular ROS Detection}

Dichlorodihydrofluorescein diacetate (DCFH-DA) is the most common probe to detect intracellular ROS [5]. Due to its excellent permeability through cell membranes, DCFH-DA easily enters the cells and it is deacetylated to form DCFH carboxylate anion. When the ROS is presented in the cells, DCFH reacts with it and forms 2',7'-dichlorofluorescein (DCF) which is fluorescent green [6]. After irradiating the cells with the NIR laser, the fluorescent images of DCF were taken, as shown in Figure 3. There were weak fluorescence images of DCF in the control group, laser only group, and PPy-MB NPs group. On the other hand, strong fluorescent images were observed in PPy-MB NPs + $808 \mathrm{~nm}$ laser group, indicating the promising effectiveness of PPy-MB NPs for the PDT.

a) Control

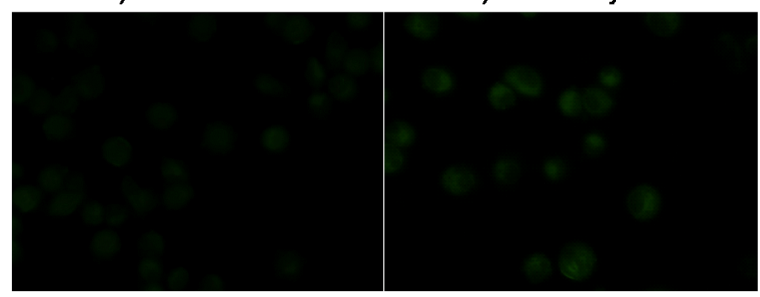

c) PPy-MB

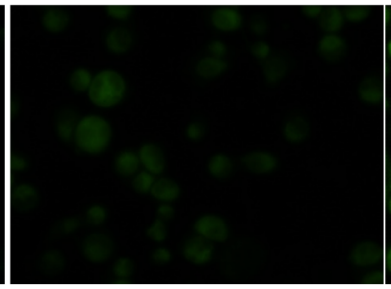

d) PPy-MB+Laser

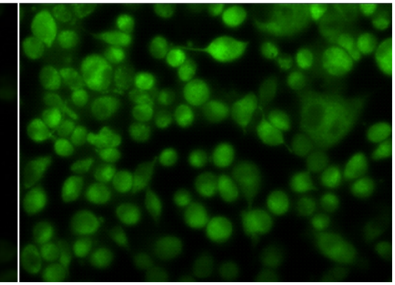

Figure 3. Fluorescence images of DCF in MDA-MB-231 cells under different conditions. (a) Control, (b) Laser only (808 nm laser), (c) PPy-MB NPs and (d) PPy-MB NPs + $808 \mathrm{~nm}$ laser. The concentration of PPy-MB NPs was $50 \mu \mathrm{g} / \mathrm{mL}$ and the $808 \mathrm{~nm}$ laser $\left(0.5 \mathrm{~W} / \mathrm{cm}^{2}\right)$ irradiation was carried out for $6 \mathrm{~min}$.

\section{Conclusions}

In conclusion, the multifunctional nanoparticles with broad NIR absorbing property were developed. PPy-MB NPs showed great potential for the deep tissue treatment using the combined photo-induced cancer therapy with a single near-infrared wavelength. In vitro tests evidenced that combined PTT and PDT treatment was more effective than individual treatment. 
Conflicts of Interest: The author declares no conflict of interest.

\section{References}

1. Oh, J.; Yoon, H.; Park, J.-H. Nanoparticle platforms for combined photothermal and photodynamic therapy. Biomed. Eng. Lett. 2013, 3, 67-73, doi:10.1007/s13534-013-0097-8.

2. Chen, M.; Fang, X.; Tang, S.; Zheng, N. Polypyrrole nanoparticles for high-performance in vivo nearinfrared photothermal cancer therapy. Chem. Commun. 2012, 48, 8934-8936, doi:10.1039/C2CC34463G.

3. Zha, Z.; Deng, Z.; Li, Y.; Li, C.; Wang, J.; Wang, S.; Qu, E.; Dai, Z. Biocompatible polypyrrole nanoparticles as a novel organic photoacoustic contrast agent for deep tissue imaging. Nanoscale 2013, 5, 4462-4467, doi:10.1039/c3nr00627a.

4. Yu, J.; Hsu, C.H.; Huang, C.C.; Chang, P.Y. Development of therapeutic Au-methylene blue nanoparticles for targeted photodynamic therapy of cervical cancer cells. ACS Appl. Mater. Interfaces 2015, 7, 432-441, doi:10.1021/am5064298.

5. Kalyanaraman, B.; Darley-Usmar, V.; Davies, K.J.A.; Dennery, P.A.; Forman, H.J.; Grisham, M.B.; Mann, G.E.; Moore, K.; Roberts Ii, L.J.; Ischiropoulos, H. Measuring reactive oxygen and nitrogen species with fluorescent probes: challenges and limitations. Free Radic. Biol. Med. 2012, 52, 1-6, doi:10.1016/j.freeradbiomed.2011.09.030.

6. Curtin, J.F.; Donovan, M.; Cotter, T.G. Regulation and measurement of oxidative stress in apoptosis. J. Immunol. Methods 2002, 265, 49-72.

Publisher's Note: MDPI stays neutral with regard to jurisdictional claims in published maps and institutional affiliations.

(c) 2020 by the authors; licensee MDPI, Basel, Switzerland. This article is an open access article distributed under the terms and conditions of the Creative Commons by Attribution (CC-BY) license (http://creativecommons.org/licenses/by/4.0/). 